\title{
Zidovudine plus interferon alfa-2b treatment in patients with HIV and chronic active viral hepatitis
}

\author{
G Visco, L Alba, S Grisetti, P Guarascio, P Narciso, P Sette, C Struglia, G Tossini, \\ V Tozzi
}

\begin{abstract}
Results are reported for a small study of 11 patients positive for HIV and with chronic active viral hepatitis. Low dose zidovudine/interferon alfa-2b combined treatment produced a general reduction in alanine aminotransferase activities and increased the CD4 lymphocyte count, hepatitis $B$ e seroconversion, and the loss of HIV p24 antigen. The treatment was well tolerated and progression of HIV disease was not seen.

(Gut 1993; supplement: S107-S108)
\end{abstract}

A study was done to evaluate the efficacy and toxicity of zidovudine plus interferon alfa-2b in the treatment of patients with HIV infection and chronic active hepatitis proved by liver biopsy examination because of hepatitis $B$ virus (HBV), hepatitis delta virus (HDV), hepatitis
L. Spallanzani Hospital for Infectious

Diseases,

Rome, Italy

G Visco

L Alba

S Grisetti

P Guarascio

P Narciso

P Sette

C Struglia

G Tossini

V Tozzi

Dr G Visco,

Infectious Diseases,

via Portuense 292,

00149 Rome, Italy.
Correspondence to:

L. Spallanzani Hospital for
$\mathrm{C}$ virus (HCV) infection, or a combination of these.

\section{Patients and methods}

For inclusion in the study, patients were required to have raised serum transaminase activities, (between 2.5 and 8 times the upper limit of normal for at least six months). Serological signs of viral replication were to be present both in HBV and in HCV (not in HDV) patients. Therefore, they had to be: (a) positive for anti-HCV antibody (ELISA) plus viral HCV-RNA (polymerase chain

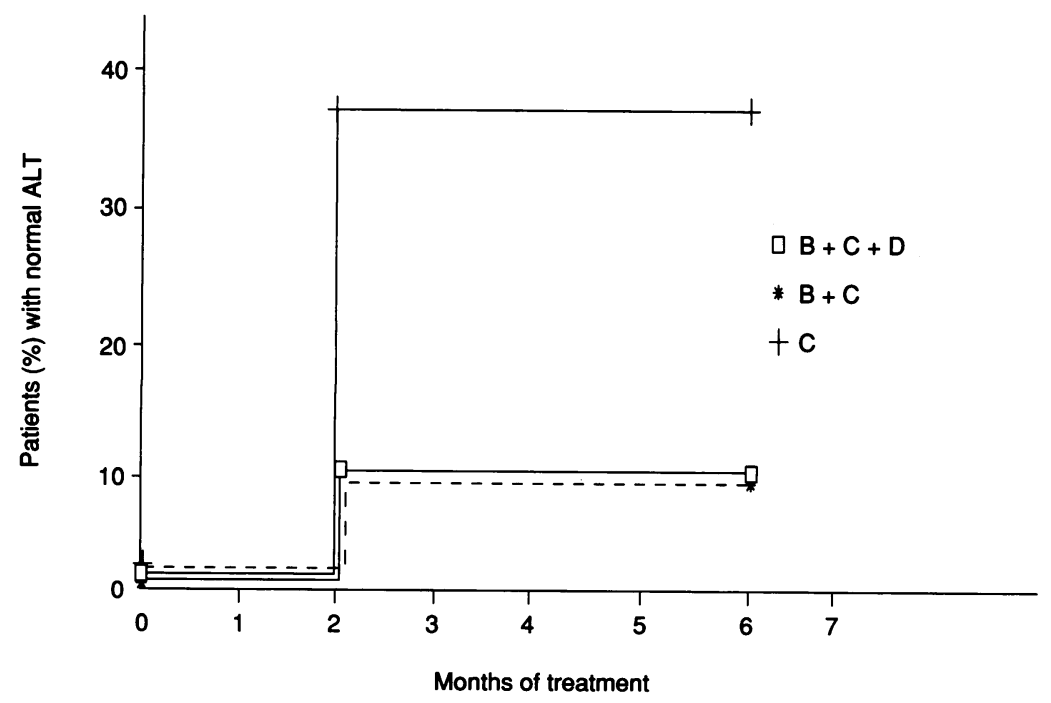

Figure 1 Normalisation of serum ALT activities. reaction (PCR)) in C hepatitis; (b) positive for hepatitis $B$ surface antigen (HBsAg) plus HBV-DNA or hepatitis B e antigen (HBeAg) in B hepatitis; (c) positive for HBsAg plus antiHDV antibody in HDV. Chronic active hepatitis proved by liver histology was required to be present not more than six months before treatment. Anti-HIV antibody positivity was shown, using ELISA and western blot, and CD4+ lymphocyte counts were to be lower than $500 / \mathrm{mm}^{3}$. All patients gave their informed consent to take part in this study.

A total of 11 anti-HIV-positive patients (nine men and two women, aged 27-33) were enrolled in the trial. Risk factors for infection consisted of heroin addiction in nine patients, homosexual contacts in one, and heterosexual contacts in one. HIV disease stage (Centers for Disease Control) classification was IV C2 in eight patients, IV $\mathrm{Cl}$ in one, and II in two patients. Testing for hepatitis viral markers showed anti-HCV alone in five patients, replicating both $\mathrm{HCV}$ and $\mathrm{HBV}$ in two, non-replicating HBV plus anti-HDV in two, and replicating both $\mathrm{HCV}$ and $\mathrm{HBV}$ plus antiHDV in two. Three patients of 11 were positive for HIV p24 antigen (HIV p24 Ag).

The five patients with HCV-related chronic active hepatitis received oral zidovudine 250 $\mathrm{mg}$ at 12 hour intervals ( $500 \mathrm{mg} /$ day) plus interferon alfa-2b 3 million units (MU) three times weekly by subcutaneous injection. The remaining six (two with $\mathrm{HBV} / \mathrm{HDV}$ related disease, two with $\mathrm{HBV} / \mathrm{HCV}$ related disease, and two with $\mathrm{HCV} / \mathrm{HBV} / \mathrm{HDV}$ related disease) each received zidovudine $500 \mathrm{mg} /$ day plus interferon alfa-2b $5 \mathrm{MU}$ three times weekly. All patients were followed up for three to 12 months.

Serum alanine aminotransferase activities (ALT), white blood cell, and platelet counts were measured every month, while $\mathrm{HBeAg}$, CD4 lymphocytes, and HIV p24 Ag were measured every third month. The clinical progression of HIV infection was assessed using the Centers for Disease Control staging system.

\section{Results}

After two months of treatment, four of 11 patients $(36.4 \%)$ had normalised serum ALT activities and by the sixth month five patients $(45.5 \%)$ had normal values (Fig 1 ). Mean ALT activities fell from $>258$ IU/l $(n=11)$ to 133 IU/1 $(n=8)$ during six months of treatment with zidovudine and interferon, with significant 
differences at three and six months compared with baseline values (Fig 2). After two months of treatment, ALT activities became normal in four of five $\mathrm{HCV}$ patients, one of two $\mathrm{HBV}+\mathrm{HCV}$ patients (and remained normal

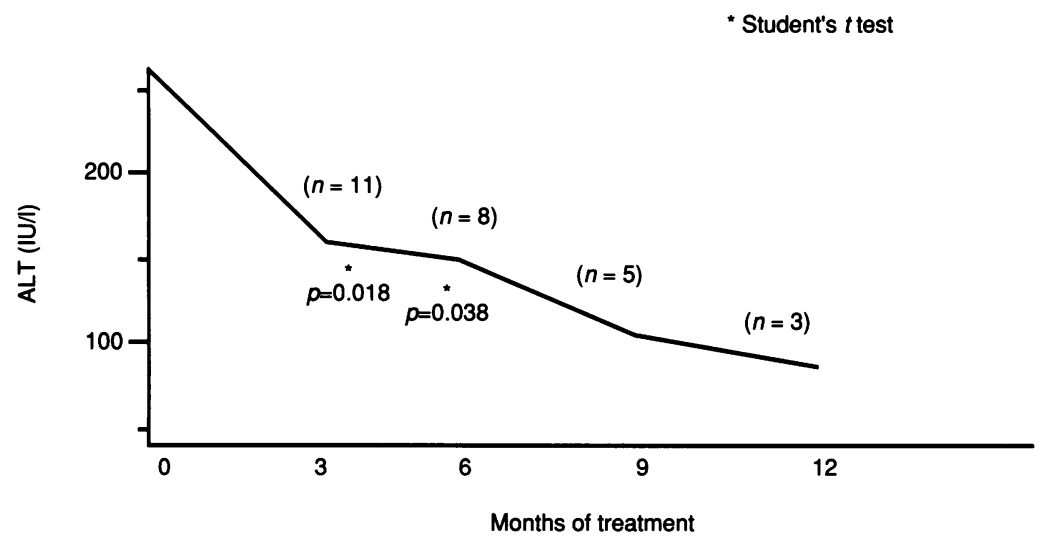

Figure 2 Mean serum ALT activities.

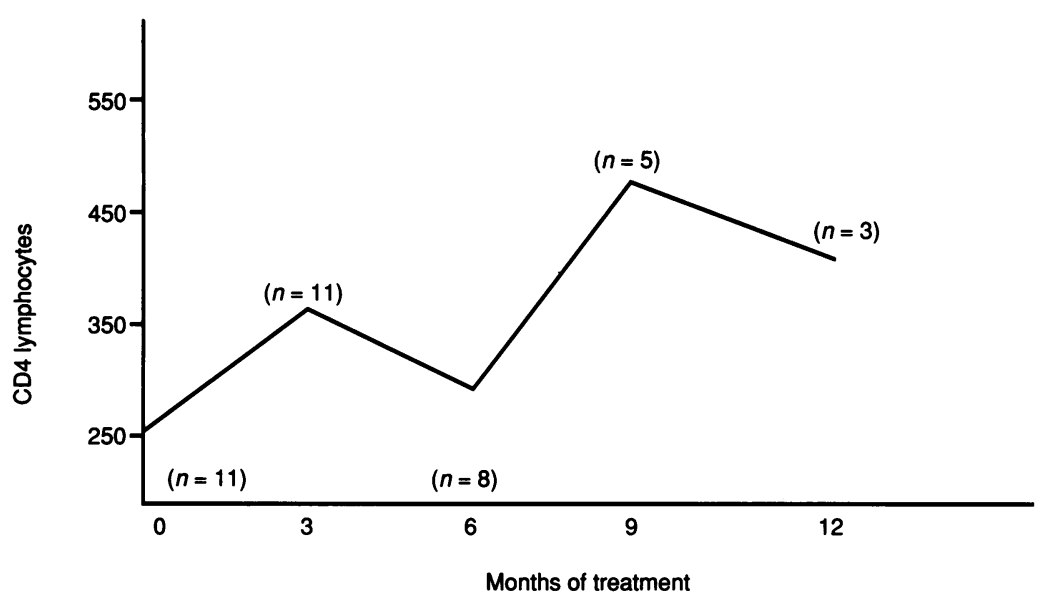

Figure 3 Mean CD4 lymphocyte values. after six months), and in one of two $\mathrm{HBV}+\mathrm{HCV}+\mathrm{HDV}$ patients. In contrast, ALT activities were almost unchanged in the two patients with disease unrelated to HCV (nonreplicating HBV/HDV-related chronic active hepatitis patients).

Mean levels of CD4 lymphocytes fluctuated during treatment with zidovudine and interferon but showed an overall tendency to increase (Fig 3). The Table shows changes in $\mathrm{HBeAg}$ and HIV p24 Ag positivity in patients continuing on treatment for up to 12 months. Three of six HBeAg positive patients seroconverted to anti-HBe, and all three HIV p24 Ag positive patients became negative within three months of treatment.) Flu like symptoms were seen in three $(43 \%)$ of seven patients treated with zidovudine $500 \mathrm{mg}$ /day plus the higher dose (5 MU three times weekly) of interferon alfa-2b. No progression of HIV related disease was seen.

\section{Conclusions}

The results of this small study in HIV positive patients with viral hepatitis suggest that combined treatment with low dose zidovudine $(500 \mathrm{mg} /$ day) and interferon alfa-2b (3 or 5 MU three times weekly) can reduce serum ALT activities, increase CD4 lymphocytes count, and promote $\mathrm{HBe}$ seroconversion, mostly in patients with $\mathrm{HBV}$ or $\mathrm{HCV}$ replicating infections or both. It also favours the loss of HIV p24 Ag.

TABLE Changes in $\mathrm{HBeAg}$ and HIV p24 Ag positivity in treated patients

\begin{tabular}{llllll}
\hline Treatment (month) & 0 & 3 & 6 & 9 & 12 \\
\hline Patients (n) & 11 & 11 & 8 & 5 & 3 \\
HBeAg positive (n) & $6 / 6$ & $6 / 6$ & $4 / 6$ & $2 / 4$ & $1 / 2$ \\
HIV p24 Ag positive (n) & $3 / 11$ & $0 / 8$ & $0 / 8$ & $0 / 5$ & $0 / 3$ \\
\hline
\end{tabular}

